\title{
Coming of Age
}

\author{
Gireesh Warawdekar
}

J Clin Interv Radiol ISVIR 2017;1:3-4.

Address for correspondence Gireesh Warawdekar, MBBS, DMRE, President, Indian Society of Vascular and Interventional Radiology (ISVIR) (e-mail: gireesh.w@gmail.com).

It gives me great pleasure to address you all in the first issue of The Journal of Clinical Interventional Radiology (JCIR).

We already had the Indian Newsletter that updated us on the happenings as well as case presentations around the country. It had always been our endeavor to start an Indian journal. A few years ago, we had attempted to start our own journal; however, it did not come to fruition.

Since the beginning of this year, Dr. Shyamkumar N. Keshava, Dr. Sanjeeva Kalva, and the entire editorial team have worked hard to give a shape and substance for our journal. I also appreciate the steadfast support of the eminent national as well as the international editorial board members; this effort was made possible entirely due to their encouragement and valuable guidance.

Initially, we plan to publish three issues of JCIR annually. We hope that in the years to come, we can convert this into a bimonthly journal. At the same time, we plan to work toward getting JCIR indexed-a feather in the cap for the Indian Society of Vascular Interventional Radiology (ISVIR).

I must congratulate all the members of the Interventional Radiology fraternity from all over India who have come forward with enthusiasm and contributed to the very first issue of JCIR per the planned timeline. In the same breath, I would like to express hope that JCIR can garner contributions from authors all around the world so that it would reflect a global knowledge base. I appeal to all the interventional radiologists in India and abroad to continue submitting research articles and case studies regularly to enable the journal to become more robust and timely.

As the President of ISVIR, I consider it a privilege to be a part of this success story.

I congratulate JCIR and its entire editorial team for successfully carrying out this herculean task and wish them good luck for the forthcoming issues.

Long live JCIR and ISVIR!!
Copyright ( 2017 by Indian Society of Vascular and Interventional Radiology 